\title{
A Study on the Realistic Path of Tourism Industry Helping Rural Rejuvenation -Taking Shaanxi Rural Tourism Demonstration Village as an example
}

\author{
Zhang $\mathrm{Yu}^{1}$ \\ ${ }^{1}$ Leisure Management School, Eurasia University, Xi'an, Shaanxi
}

\begin{abstract}
The vigorous development of rural tourism has played an important role in promoting the agricultural economy, improving the rural living environment, inheriting and protecting rural culture, and has become an important way to promote the implementation of rural revitalization strategies. The paper investigates the relationship between the rural tourism industry and rural revitalization. Taking the rural tourism demonstration village in Shaanxi Province as an example, the impact of rural tourism development in Shaanxi on rural revitalization is analyzed, and the development path of rural tourism to promote rural revitalization is developed to provide a reference for other regions.
\end{abstract}

\section{Introduction}

The key to solving the issues of "agriculture, rural areas and farmers" lies in the implementation of the rural revitalization strategy. The development of rural tourism industry is an important way to implement the strategy of rural revitalization. The development of the rural tourism industry can effectively guide and promote the flow of capital, talents, information, technology, management and other elements to the rural geographical space, promote the integrated development of primary, secondary and tertiary industries in rural areas, and optimize the urban and rural system and spatial layout, thereby promoting the construction and revitalization of the rural areas.

\section{Connotation and interrelationship between rural tourism industry and rural revitalization}

\subsection{Related research on rural tourism industry}

Rural tourism relies on the rural natural features, good ecological environment, unique cultural customs, and original agricultural products to meet the needs of urban residents to return to nature and relax.

The "village transformation" promoted by the developed countries in Europe and the United States and the "new village movement" launched by South Korea are all valuable in implementing the "government-guided, common-led" development model. In the rural revival movement, Japan not only focused on the development of environmental conservation agriculture and organic agriculture, but also paid special attention to the coordination of construction projects and the natural environment in rural planning, governance and construction.

The initial development of the rural tourism industry in Europe was to save the rural crisis and revitalize the rural economy. Karol found that the development of rural tourism industry played an important role in optimizing industrial structure, improving infrastructure, and increasing residents' income [1]. With the development and research of the rural tourism industry, scholars began to pay attention to the positive role of the rural tourism industry in the social culture and ecological environment. The study found that the development of rural tourism is conducive to promoting cultural exchanges between the countryside and the outside world, promoting community solidarity and industrial structure optimization, promoting local cultural development, and improving the rural development environment [2]. However, some scholars believe that rural tourism enterprises have the problems of small scale, low employment level, low income, and limited contribution to local economy [3]. By studying the development of rural tourism in southern Germany, Oppermann found that rural tourism can not only provide more employment opportunities, but also help to change the traditional concepts of residents and develop the local economy. However, the disadvantages of rural tourism are also obvious, including small scale and seasonal Great influence [4].

There are also many scholars in China discussing the impact of rural tourism on agricultural development. Tang Jianxiong's research found that rural tourism plays a positive role in promoting the construction of new countryside and alleviating the living pressure of residents [5]. Mei Xuemei and others found that rural tourism has played an active role in improving the level of rural economic development, promoting urban and rural 
development, and improving the rural living environment [6]. Meng Fanying and others found that the development of rural tourism has promoted a new way of economic growth in rural areas, and the increase in local residents' income is no longer dependent on government support. The residents' sense of well-being and belonging have increased, but at the same time, the development of the tourism industry has also brought some negative effects such as increased cost of living, widening the gap between rich and poor, and environmental pollution [7]

\subsection{Connotation of rural revitalization strategy}

Rural revitalization is based on ensuring rural economic development and comprehensively improving the development level of rural culture, ecology and people's livelihood. The requirements of the rural revitalization adhere to the seven principles of the Party's management of rural work, the priority development of agriculture and the countryside, the leading position of farmers, the overall revitalization of the countryside, the harmonious coexistence of man and nature, the integrated development of urban and rural areas and local conditions, and finally achieve the goal of "prosperous industry, ecological and livable environment, rural civilization, effective governance, and affluent life" [8].

Prosperous industry is the core of rural revitalization, and its focus is to extend the industrial chain, improve development levels, optimize industrial structure, promote industrial transformation and upgrading, and provide more employment opportunities for farmers. Ecological and livable environment is the key. The countryside has unique natural conditions and topography. A good ecological environment is the greatest advantage and precious wealth of the countryside. We must respect nature, conform to nature, protect nature, and realize the harmonious coexistence between man and nature. Rural civilization is the soul of rural revitalization. Through education and guidance, villagers learn to improve their own qualities, promote social ethics, professional ethics and personal morality, and build a beautiful village where everyone is polite, understands courtesy, loves elderly and children and helps each other. Effective governance is the foundation of rural revitalization, increasing the participation of villagers and continuously improving the level of rural governance. Affluent life is the foundation of rural revitalization, improving the rural public employment service system, improving the rural people's livelihood security level, expanding farmers' income growth channels, narrowing the gap between urban and rural areas, and achieving prosperity [9].

\subsection{Relationship between the development of rural tourism industry and rural revitalization}

(1) The development of rural tourism industry is consistent with the development goals of rural revitalization. The development of rural tourism is conducive to expanding the industrial chain, expanding job posts, increasing farmers' participation and farmers' income, and improving living standards. By building a modern agricultural industry system, we will promote agriculture from increasing production to improving quality.

(2) The development of rural tourism industry trains talents for rural revitalization. Talent cultivation is the "booster" of the rural revitalization strategy, which is conducive to evoking the vitality of talent innovation and entrepreneurship. At present, the changes in the rural population structure, the lack of labor, and the brain drain have continuously reduced the vitality of the village. The huge rural leisure and holiday market has attracted young people from home and abroad to return to their hometowns for entrepreneurship. To promote the efficiency of idle business households, government agencies have organized a number of outstanding rural tourism operators by organizing management training, policy incentives and other measures.

(3) The development of rural tourism industry is conducive to the revitalization of rural culture. Rural culture and folk culture are the soul of rural tourism development, which attracts urban residents to return to their original nature and retrieve their childhood memories. At the same time, it also brings civilized living habits and open thinking to the countryside, which is not only conducive to the inheritance of rural culture, but also enhances the civilization of the villagers.

(4) The development of rural tourism industry is conducive to the construction of rural organizations. Realizing the rapid development of rural tourism needs to the model role of rural grassroots party organizations. From the perspective of development practice, cadres stationed at the grassroots level encourage and help villagers build tourism infrastructure, engage in tourism business activities, and drive farmers to become rich. At the same time, they have also strengthened the construction of rural grassroots party organizations, consolidated the construction of party members, and improved the quality of rural cadres and rural party members.

(5) The development of rural tourism industry is conducive to improving the supply of rural public services. The increasing demand for rural public services and public facilities and the imbalance between the supply and demand of rural public services are widespread. The development of rural tourism has not only promoted the construction of rural transportation and infrastructure, but also promoted the construction of public service facilities such as sports, recreation, and the creation of the environment. 


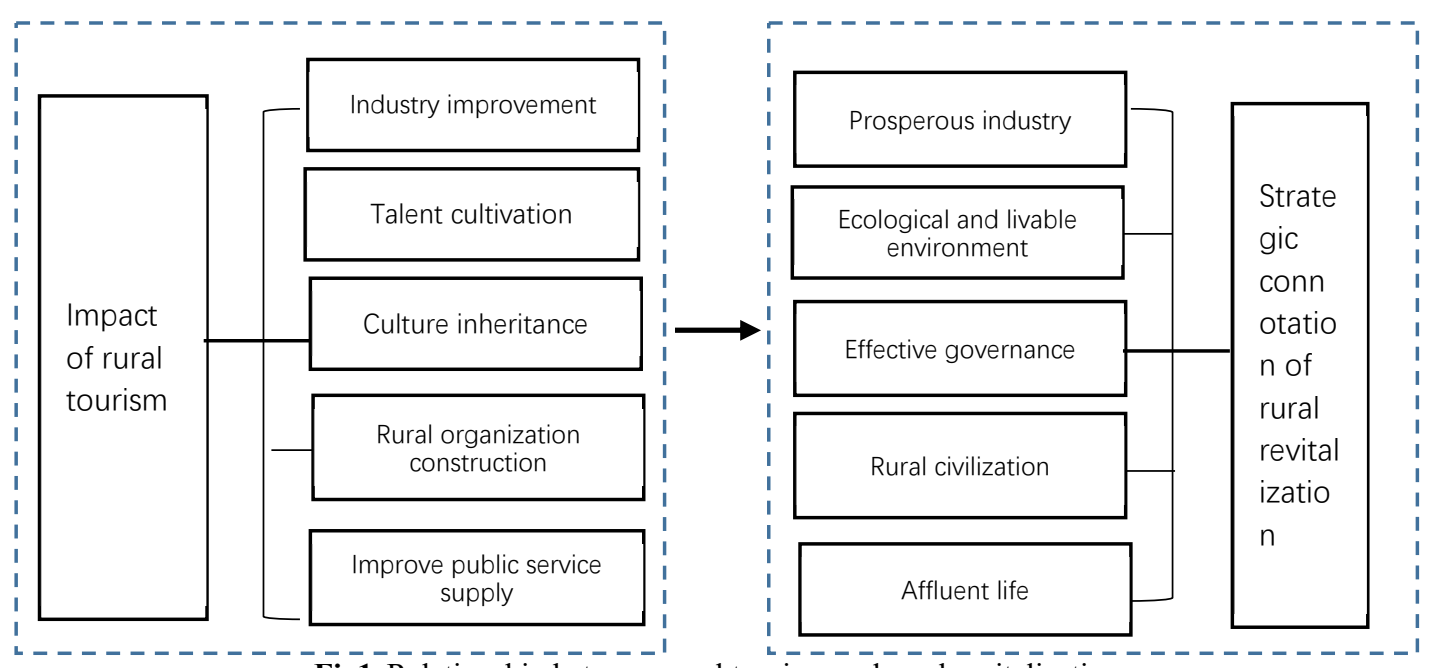

Fig1. Relationship between rural tourism and rural revitalization

\section{Impact of rural tourism development on rural revitalization in Shaanxi Province}

\subsection{Development status of rural tourism industry in Shaanxi Province}

Shaanxi Province is located in the western hinterland, with a total area of $205,800 \mathrm{~km}^{2}$. There are 11 cities under the jurisdiction of the province, which are divided into three regions: Northern Shaanxi Plateau, Guanzhong Plain and Southern Shaanxi. As China's agricultural leisure tourism enters a golden period of rapid development, Shaanxi Province has rich rural tourism products, large tourist scale, high industry development maturity and rapid development, ranking second in all key provinces in the country. Yuanjia Village and Tangyu Town, Qingmuchuan Ancient Town and other batches of rural tourism demonstration villages have great influence in the country.

The rural tourism industry has become an important driving force for Shaanxi to promote rural revitalization. In recent years, Shaanxi regards the development of the rural tourism industry as an important starting point for the goal of strong agriculture, rich farmers, and beautiful rural areas. It gathers the policy guidance, planning leading, standard construction, pilot sites, example construction, cultural improvement, brand promoting and training improvement to promote the sustainable and rapid development of rural tourism industry comprehensively and systematically.

According to the data released by the Shaanxi Provincial Tourism Development Committee, there are 27 model villages of rural tourism in China, 30 model households of rural tourism, 20,000 farmhouse operating households, nearly 240,000 rural tourism industry employees. The average annual income of farmhouse operating households is basically more than 50,000 yuan, and the average annual income of employees is more than 20,000 yuan. Rural tourism operating income in some areas has accounted for more than $30 \%$ of the local agricultural output value. The tourism industry has driven traditional agriculture and driven local farmers out of poverty.

In the context of the continuous development and enrichment of rural tourism resources and the continuous strengthening of brand publicity, Shaanxi Province received 707 million domestic and foreign tourists in 2019, an increase of $12.2 \%$ year-on-year, and total tourism revenue of 720 billion yuan, an increase of $20.11 \%$. In the first half of 2019, the total number of rural tourism in the country exceeded 1.5 billion, a year-on-year increase of $10.2 \%$. In the first three quarters of 2019 , rural tourism in Shaanxi received a total of 259 million people, an increase of $20.1 \%$ year-on-year, and tourism revenue was 39.68 billion yuan, an increase of $28.1 \%$ year-on-year. The growth rate of rural tourism exceeded the overall growth rate of tourism in Shaanxi Province and also exceeded the overall growth rate of rural tourism in the country.

\subsection{Impact of rural tourism industry on rural revitalization}

Since the 18th National Congress proposed the construction of beautiful villages in 2013, Shaanxi has advocated the development of rural tourism based on a long history and strong folk culture. The development of rural tourism in Shaanxi Province has a positive effect on the development of the local economy, the improvement of income levels, and the adjustment of the industrial structure.

According to the statistics released by Shaanxi Province, from 2013 to 2019, the GDP of Shaanxi Province increased from 1620.5 billion yuan to 2579.3 billion yuan, a 1.6-fold increase. The proportion of primary industry continued to decline, and the proportion of tertiary industry increased year by year. In 2019, the ratio of primary industry to GDP in Shaanxi Province decreased from $9 \%$ in 2013 to $7.72 \%$, and the ratio of tertiary industry increased from $36 \%$ in 2013 to $45.83 \%$ (see Figure 2). The per capita disposable income of rural residents increased from 7,092 yuan to 12,326 yuan, an increase of $73.8 \%$ month-on-month (see Figure 3 ). The income ratio of urban and rural residents also fell from 3.15:1 in 2013 to $2.93: 1$ in 2018 . 

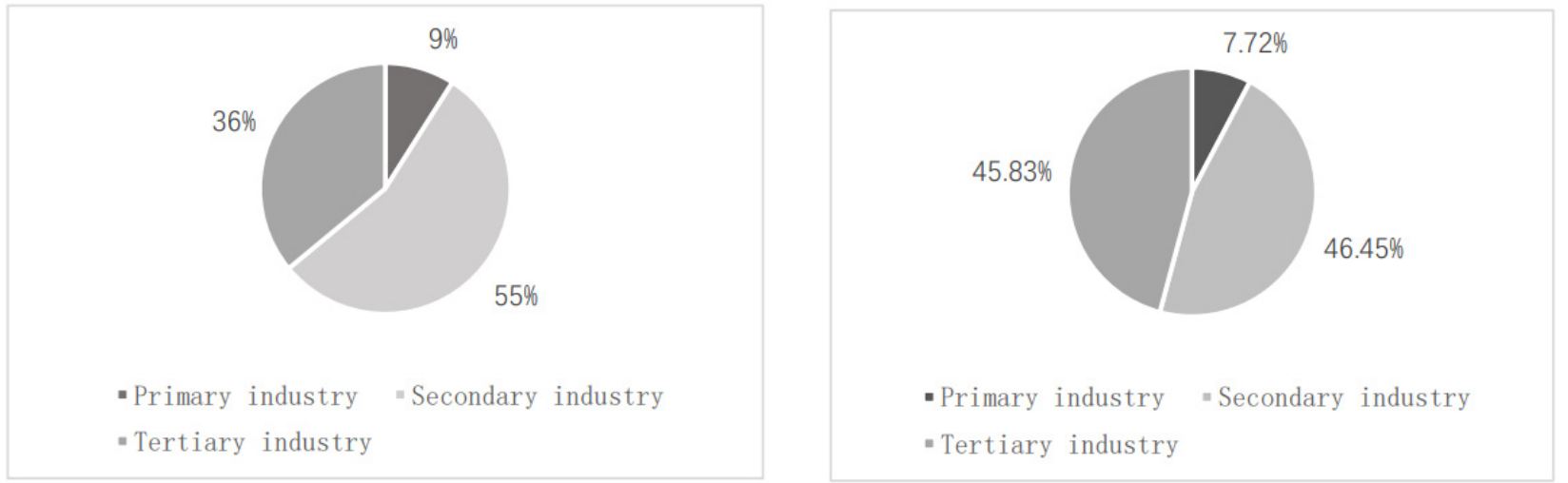

Fig2. Proportion of three major industries in Shaanxi Province from 2013 to 2019

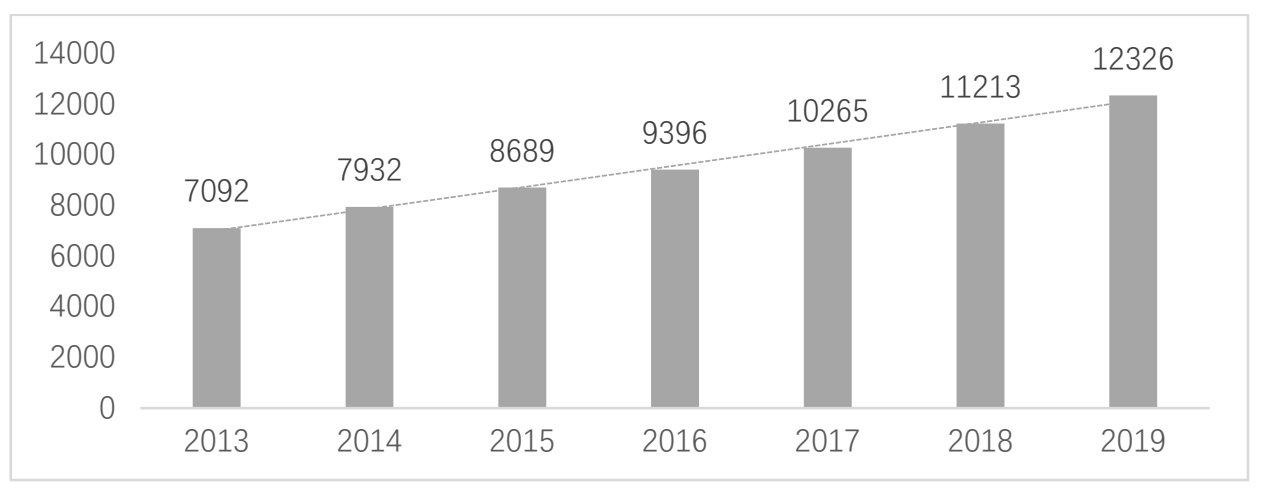

Fig3. Disposable income of rural residents in Shaanxi Province from 2013 to 2019

The development of the rural tourism industry has promoted the adjustment of the industrial structure and product structure in rural areas, forming a high-valueadded economic industry, and effectively promoting the development of rural industrialization. The needs of tourists in terms of traffic, food, housing, travel, shopping, entertainment, etc. drive the development of agricultural and sideline products industry, handicraft industry, transportation industry and real estate and other related industries, and then promote the structural adjustment of rural areas and change the economic growth mode, realizing the goal of "production development".

The rural tourism industry is a service industry. Operators need to be familiar with and master basic service etiquette and attitudes, as well as market competition awareness. The interaction between urban residents and rural residents has brought many new ideas and new information from the city to the countryside, and it has had a subtle influence on farmers. Some conditional residents have begun to consciously learn the new culture, new technologies, Mandarin, and comprehensively improve farmers' quality, to achieve the goal of "rural civilization". At the same time, government agencies take the lead in organizing training in rural tourism management, tourist reception services, etc., to provide more farmers with demonstrations, and promote the transition from traditional low-quality farmers to highquality farmers.

\section{Realistic path of rural tourism industry helping rural revitalization strategy}

\subsection{Enhance industrial vitality through industrial integration and interaction}

The development of the rural tourism industry has realized the organic integration of agriculture and tourism, and will inevitably lead to the supporting development of transportation, commerce, catering, hotels, agricultural products processing industry and tourism commodities. For example, Chenlu Ancient Town in Yintai District, Tongchuan City is one of the birthplaces of China's ancient famous Yaozhou porcelain. It combines the pottery industry with tourism, and the sharing of pottery technology and agriculture has promoted the better use of rural resources and realized the linkage of industry, agriculture, service industry and tourism industry. It achieves the interaction between industry and industry, industry and culture, industry and tourism, and provides tourists and residents with a full industry chain experience. For example, Yuanjia Village, after more than ten years of development, has organically integrated agriculture, tourism and cultural industries, developed farmhouse tourism circle with Guanzhong quadrangle as the core, leisure tourism products such as bar streets and snack streets, Guanzhong experience tourism program with Guangzhong Intangible Cultural Heritage Museum as the core. 


\subsection{Continuously iterate the development model of rural tourism and expand all-for-one tourism}

With the social and economic development and changes in life, the needs of urban and rural residents for leisure tourism consumption are constantly changing. The closeness to nature, leisure, recreation, keeping physical and mental health, etc. have become the main motives for mass leisure tourism. To meet the needs of urban and rural residents for leisure tourism, the development model for rural tourism needs to be constantly upgraded and improved.

From the beginning of the 1990 s to the present, the development of rural tourism in Shaanxi has experienced the period of "farmhouse operating household", period of idyllic sightseeing, period of folk cultural experience, period of agriculture + tourism, and period of construction of "beautiful countryside". The development model is different in each period, and a number of demonstration areas have emerged, such as Shangwang Village in Chang'an District, Yuanjia Village in Liquan County, Chenlu Ancient Town in Yintai District, Tongchuan City, Fengcun Town in Dali County, and Zhushui County Zhu Jiawan Village.

Since the 13th Five-Year Plan period, Shaanxi has proposed to regard all-for-one tourism as a new dynamic for regional economic and social development. The allfor-one tourism development model is based on the development of high-quality tourism, perfecting the product system in the tourism supply system, integrating agriculture, culture, sports and other industries, integrating tourism elements such as food, accommodation, traveling, shopping and entertainment, commerce, keeping health, learning, leisure, and novelty, developing new products and extending the industrial chain. For example, Dali County, an all-for-one tourism demonstration county in Shaanxi Province, revolves around the theme of "tourism + sports", relies on the natural scenery of the country, builds sports tourism facilities, and enhances its popularity at home and abroad by hosting a series of sports events such as the world famous school dragon boat race.

\subsection{Main construction by administrative department and leading by community to promote development together}

Rural tourism destinations are different from other tourism destinations, and have the particularity of cross-sector and cross-industry. Relevant government departments should undertake things that cannot be achieved by relying on the market and scattered farmers in the process of rural tourism development, such as rural tourism overall development planning, infrastructure construction, establishment of investment and financing channels, talent training, brand promotion, marketing, to implement quality assessment standards. In order to promote the development of rural tourism in Shaanxi Province, the tourism and agricultural departments jointly established the "Shaanxi Provincial Rural Tourism Leading Group" to coordinate the promotion and leadership of rural tourism development in Shaanxi Province. To improve the service quality of rural tourism, the tourism administrative department has formulated the "Shaanxi Rural Tourism Demonstration Village Evaluation Standards". By the end of 2019, 33 provincial tourism demonstration counties, 150 tourism-specific towns, and 268 rural tourism demonstration villages have been created. More than 20,000 farmhouses, more than 1,000 characteristic homestays and $124 \mathrm{~A}-$ level rural folk scenic spots, played a leading role in demonstration. Some of the sites were selected as "Shaanxi Top Ten Rural Tourism Belts", "Shaanxi Top Ten Rural Tourist Scenic Spots", "Shaanxi Top Ten Charming Villages", and promoted the development of rural tourism in Shaanxi through the demonstration effect.

In the process of rural tourism development, the contents of community residents' participation in tourism development must penetrate into all levels, from individual participation to group participation, organization participation, and gradually realize full community participation. For example, one of the main factors for the success of Yuan Village is the leadership of the cadres and the participation of the villagers. Yuan Village uses villages as the carrier and farmers as the main body to drive villagers to participate in the provision of tourism products, reduce population outflows, effectively solve social problems such as left-behind elderly and leftbehind children, and live and work in peace.

\subsection{Adapt to local conditions to achieve sustainable development}

In recent years, many local governments have regarded the development of the rural tourism industry as a major poverty alleviation project development, and regard it as a new economic growth point. The focus on economic benefits has led to problems such as the abuse of cultural relic resources, the destruction of natural resources, and the alienation of rural culture. According to the World Tourism Organization's definition of sustainable tourism, the sustainability of rural tourism refers to the sustainable development of the rural economy, the sustainable development of the rural environment, the sustainable development of the rural community and the sustainable development of the rural culture.

The overall distribution of rural tourism demonstration villages in Shaanxi Province is uneven. There are 132 in Guanzhong, which are clustered in villages, 96 in southern Shaanxi, and evenly distributed, and 40 in northern Shaanxi, which are distributed.

The development model of rural tourism in Guanzhong is mainly based on Guanzhong folk market towns, such as Yuanjia Village, Maweiyi and Bailucang, with Guanzhong Folklore as the theme. The development of sustainable rural tourism is based on protection. The most fundamental goal is to improve the living standard and happiness index of local residents and inherit rural culture. The Rural Tourism Development Co., Ltd. Was established on Yuanjia Village to systematically plan and design rural tourism, and display Guanzhong folk culture and intangible cultural heritage culture through manual workshops and performances.

Southern Shaanxi is dominated by mountains, from the 
Qinling Mountains in the north, to the Daba Mountains in the south, and the Han River Valley in the middle. Rural tourism development relies on natural resources, and the vulnerability of mountain ecological environment is fully considered in rural tourism planning and development. For example, Houwan Village in Shangluo City is not conducive to the development of large-scale modern agriculture due to the mountainous regional environment, but the original natural scenery and good ecological environment are its advantages. Under the premise of protecting ecology, it has created a "Slow" culture, highlighting traditional ecological agriculture, developed green catering, traditional houses, walking, horse-drawn transportation.

Northern Shaanxi has diverse cultures, bringing together revolutionary traditional culture, northern Shaanxi folk culture, farming culture, and grassland nomadic culture. The sustainable development of rural tourism in northern Shaanxi, through the promotion of the value of revolutionary culture and folk culture, inspires the local residents' pride in their location and local culture. For example, Yan'an City trains frontline service personnel in the tourism industry, establishes the concept of "Everyone is the Yan'an Tourism Image Ambassador", introduces visitors to Yan'an's history and culture, customs, special accommodation, and special catering snacks, which deepens tourists' cultural awareness.

\section{Acknowledgment}

2017 Special Scientific Research Project of Education Department of Shaanxi Province (17JK1026): Investigation and Research on spatial pattern and Innovation Mode of "agritainment" Tourism development in Shaanxi Province.

\section{References}

1. Karol Król . Marketing Quality of Texts Posted on the Websites of Rural Tourism Facilities in Poland [J] . Economic and Regional Studies, 2018, 11 (4) 105

2. José Manuel Guaita Martínez, José María Martín Martín, JoseAntonio Salinas Fernández, et al .An analysis of the stability of rural tourism as a desired condition for sustainable tourism $[\mathrm{J}]$. Journal of Business Research, 2019, 100 (4)

3. Fleischer A, Felsenstein D . Support for Rural Tourism: Does It Make a Difference $[\mathrm{J}]$. Annals of Tourism Research, 2000, 27 (4) : 1007-1024 .

4. Martin Oppermann . Rural tourism in Southern Germany [J] .Annals of Tourism Research, 1996, 23 (1) 86 -102 . J. Clerk Maxwell, A Treatise on Electricity and Magnetism, 3rd ed., vol. 2. Oxford: Clarendon, 1892, pp.68-73.

5. Jian-xiong tang. Discussion on the Livelihood effect of Rural Tourism [J]. Journal of tourism, 2010,25 (09):6-7
6. Mei Xuemei, Yan Wenhua. Discussion on the traveldriven rural revitalization paths -- Taking Xinyang Shihe River District as an example [J]. Holiday Travel, 2018(7):115-117.

7. Fan-ying meng, Feng yuling. A Study on The Effect Assessment of Rural Tourism on Poverty Alleviation -- A Case study of Tiangang Village [J]. Modern Business, 2018 (13):190 192.

8. Yang Zhangwen. A Study on Domestic Rural Revitalization Strategy since the 19th National Congress: Literature Review and Future Prospects [J]. Contemporary Economic Management,2020(49):6.

9. Li Hongbo et al. Discussion on the realistic Path of rural tourism driving rural revitalization -- A case study of Yuanjiacun, Shaanxi Province [J]. Liaoning Agricultural Science,2020, 1st issue :63-64. 